\title{
RANCANG BANGUN SISTEM INFORMASI PENGELOLAAN DATA BPJS KESEHATAN KARYAWAN BERBASIS WEB PADA PT GAJAH TUNGGAL TBK TANGERANG
}

\author{
Eka Wulansari Fridayanthie \\ Manajemen Informatika, AMIK BSI Tangerang \\ eka.ewf@bsi.ac.id
}

\begin{abstract}
To facilitate data management BPJS Health employee PT Gajah Tunggal Tbk Tangerang, required a software that can manage BPJS Health data. Based on these problems, it is necessary to do the analysis so that the results can be obtained with the discovery of the necessary needs for software built. Analysis is done by analyzing the needs, users and facilities needed by the built software is really useful. Based on the results of problem analysis that has been done before, it can be designed a software by doing data analysis using software paradigm in waterfall. Based on the results can be concluded that, has succeeded in making software Management Information system that can assist in managing data BPJS Health employees and can display information required by users of $P T$ Gajah Tunggal Tbk Tangerang.
\end{abstract}

\section{Keywords: System, Information, Management, BPJS Health.}

Abstrak - Untuk memudahkan pengelolaan data BPJS Kesehatan karyawan PT Gajah Tunggal Tbk Tangerang, dibutuhkan suatu perangkat lunak yang dapat mengelola data BPJS Kesehatan. Berdasarkan permasalahan tersebut, maka perlu dilakukan analisis sehingga dapat diperoleh hasil dengan ditemukannya kebutuhan-kebutuhan yang diperlukan untuk perangkat lunak yang dibangun. Analisis dilakukan dengan cara menganalisis kebutuhan, pengguna dan fasilitas yang dibutuhkan oleh perangkat lunak yang dibangun benar-benar bermanfaat. Berdasarkan hasil analisis permasalahan yang telah dilakukan sebelumnya, maka dapat dirancang suatu peangkat lunak dengan melakukan analisis data menggunakan paradigma perangkat lunak secara waterfall. Berdasarkan hasil dapat disimpulkan bahwa, telah berhasil membuat perangkat lunak Sistem Informasi pengelolaan yang dapat membantu dalam mengelola data BPJS Kesehatan karyawan dan dapat menampilkan informasi yang dibutuhkan oleh pengguna PT Gajah Tunggal Tbk Tangerang.

\section{Kata Kunci: Sistem, Informasi, Pengelolaan, BPJS Kesehatan.}

\section{A. PENDAHULUAN}

Kemajuan teknologi komputer sebagai pendukung pemrosesan data dan informasi telah menjadi kebutuhan pokok perusahaan. Instansi jasa pelayanan yang memberikan pelayanan kepada karyawannya, sangat membutuhkan kecepatan pelayanan informasi, sehingga dapat memberikan pelayanan yang optimal kepada karyawannya. Setiap instansi perusahaan, pemerintah maupun pendidikan pasti membutuhkan suatu sistem informasi di dalam menjalankan aktivitas kerjanya sehingga lebih teratur dan terarah dengan waktu yang lebih efisien. Dengan adanya komputer sebagai alat untuk mengolah data, maka semua bidang dalam suatu perusahaan dapat merencanakan bidang-bidang yang dianggap penting dan utama karena hal ini dapat mendukung keberhasilan dalam suatu perusahaan dalam mencapai tujuan yang diharapkan. PT Gajah Tunggal Tbk merupakan salah satu perusahaan yang telah memakai sistem informasi berupa pemakaian perangkat komputer dalam menjalankan aktivitas kerjanya, khususnya pada pengelolaan data BPJS Kesehatan karyawan, tetapi dikarenakan penggunaannya hanya sebatas Microsoft excel, data yang ada masih tersimpan secara acak dan belum teratur dalam satu penyimpanan. Maka dari itu dibutuhkan suatu sistem yang mempermudah dalam mencari maupun mengolah data tersebut untuk memuat data yang lebih teratur, yang kelak akan berguna di dalam perusahaan terutama bagi orang yang berhubungan langsung dengan sistem tersebut untuk menunjang kinerjanya. Adapun sistem yang akan dibuat adalah suatu sistem informasi berbasis web dengan menggunakan bahasa pemrograman PHP dengan menggunakan database Mysql.

\section{B. TINJAUAN PUSTAKA}

Menurut Tantra (2012) "Sistem informasi adalah cara yang terorganisir untuk 
mengumpulkan, masukkan, dan memroses data dan menyimpannya, mengelola, mengontrol dan melaporkannya sehingga dapat mendukung perusahaan atau organisasi untuk mencapai tujuan" dan Menurut Rosa dan M.Shalahuddin (2014) "UML (Unified Modeling Language) adalah salah satu standar bahasa yang banyak digunakan di dunia industri untuk mendefisinikan requirement, membuat analisi dan desain, serta menggambarkan arsitektur dalam pemrograman berorientasi objek"

\section{METODE PENELITIAN}

Untuk mendaftarkan diri menjadi peserta BPJS Kesehatan yang terdaftar di PT Gajah Tunggal Tbk, karyawan harus mengisi form pendaftaran terlebih dahulu. Form pendaftaran harus dilengkapi dengan lampiran fotokopi Kartu Keluarga (KK) dan fotokopi Kartu Tanda Penduduk (KTP). Form pendaftaran beserta lampiran yang sudah diisi lengkap diberikan kepada staff $H R$ Operational yang menangani BPJS Kesehatan. Setelah menerima form pendaftaran dari karyawan, staff yang bersangkutan menginput ke dalam file excel kolom 34 yang sudah menjadi ketentuan dari BPJS Kesehatan. Staff tersebut mengirim data pendaftaran setiap bulannya pada tanggal 20 ke BPJS Kesehatan melalui email. Setelah mengirim data pendaftaran, maka BPJS Kesehatan akan memberikan feedback mengenai data yang dikirimkan, yang berisikan karyawan yang berhasil dan gagal validasi. Untuk karyawan yang gagal validasi, maka staff yang bersangkutan melakukan pemanggilan kepada karyawan untuk melengkapi kembali persyaratan yang dibutuhkan dan bagi karyawan yang berhasil validasi akan terdaftar serta mendapatkan kartu BPJS Kesehatan di pertengahan bulan setelah perusahaan membayar tagihan iuran.

\section{HASIL DAN PEMBAHASAN}

Berikut adalah activity diagram dari proses pedataan BPJS yang dijalankan di PT. Gajah Tunggal tbk Tangerang,

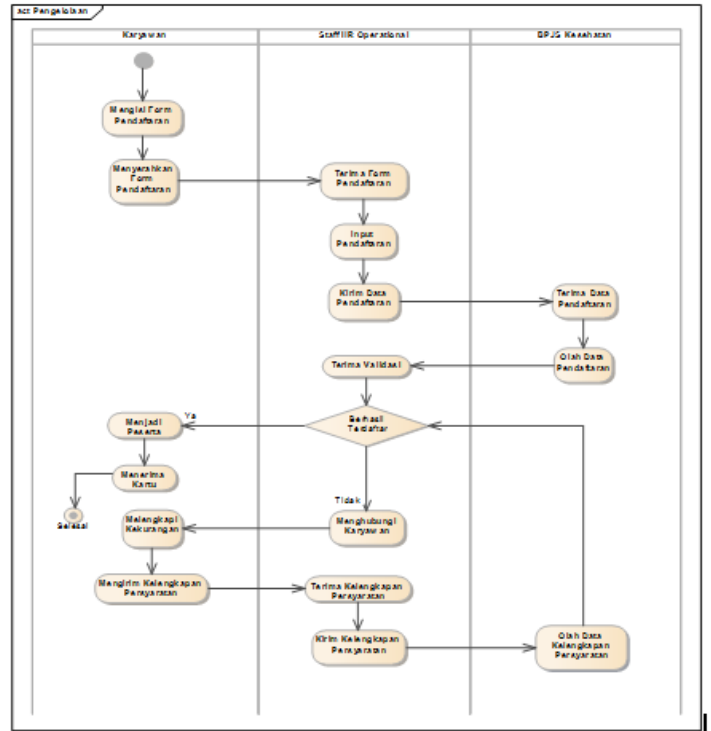

Gambar 1. Activity Diagram Pendataan BPJS PT. Gajah Tunggal tbk Tangerang

Analisis kebutuhan perangkat lunak (sofware requitment analysis) merupakan aktivitas awal dari siklus pengembangan perangkat lunak (sofware). Untuk proyekproyek perangkat lunak yang besar, analisis kebutuhan di laksanakan setelah tahap rekayasa sistem atau informasi dan sofware project planning. Sistem informasi berbasis intranet dapat memudahkan dalam mengakses informasi pengelolaan data BPJS Kesehatan. Sistem informasi berbasis intranet dapat memudahkan dalam mengakses informasi pengelolaan data BPJS Kesehatan. Berikut ini adalah spesifikasi kebutuhan (system requiretment) dari sistem pengelolaan data BPJS Kesehatan

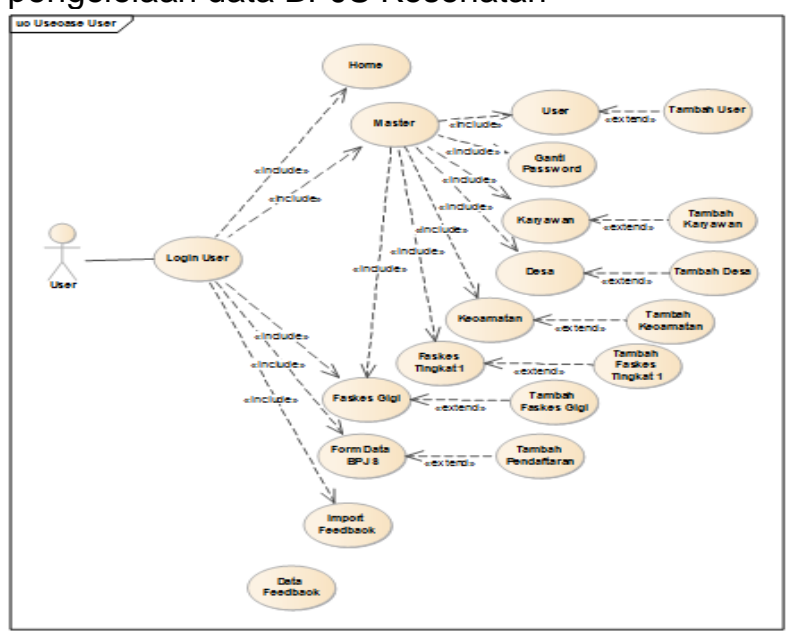

Gambar 2. UseCase Halaman User

Berikut adalah penggambaran dari activity diagram dari pengelolaan data BPJS yang dijalankan di PT. Gajah Tunggal Tbk 


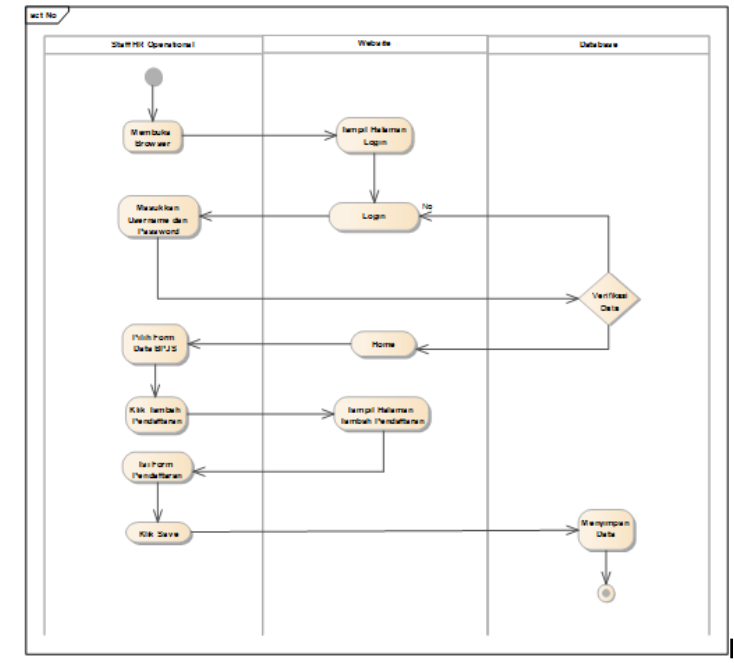

Gambar 3. Activity Diagram Pengelolaan Data

Berikut adalah user interface dari perancangan pengelolaan data BPJS yang dibuat:

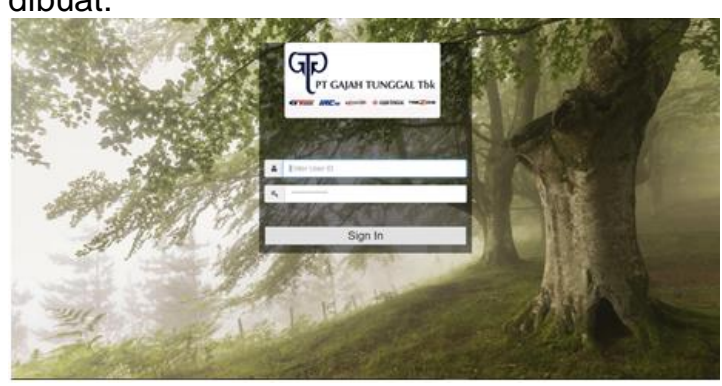

Gambar 4. User Interface Halaman Login

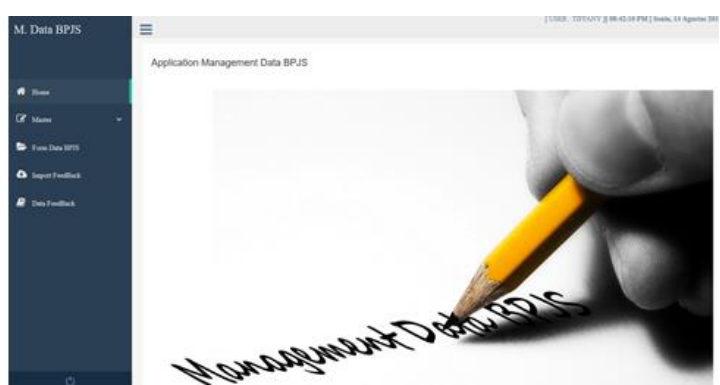

Gambar 5. User Interface Halaman Home

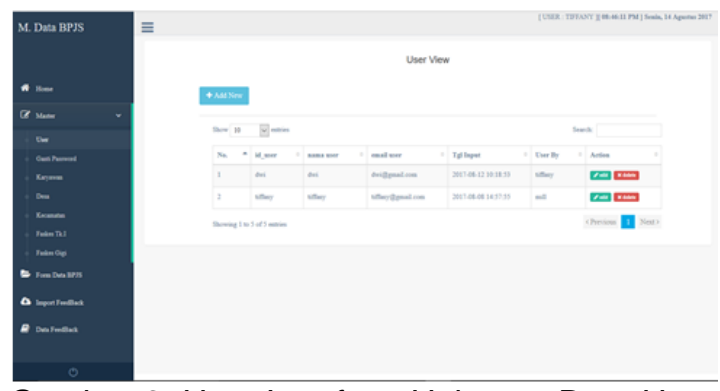

Gambar 6. User Interface Halaman Data User

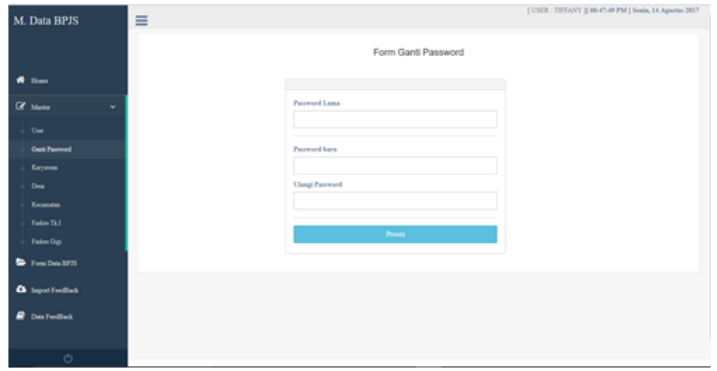

Gambar 7. User Interface Ganti Password
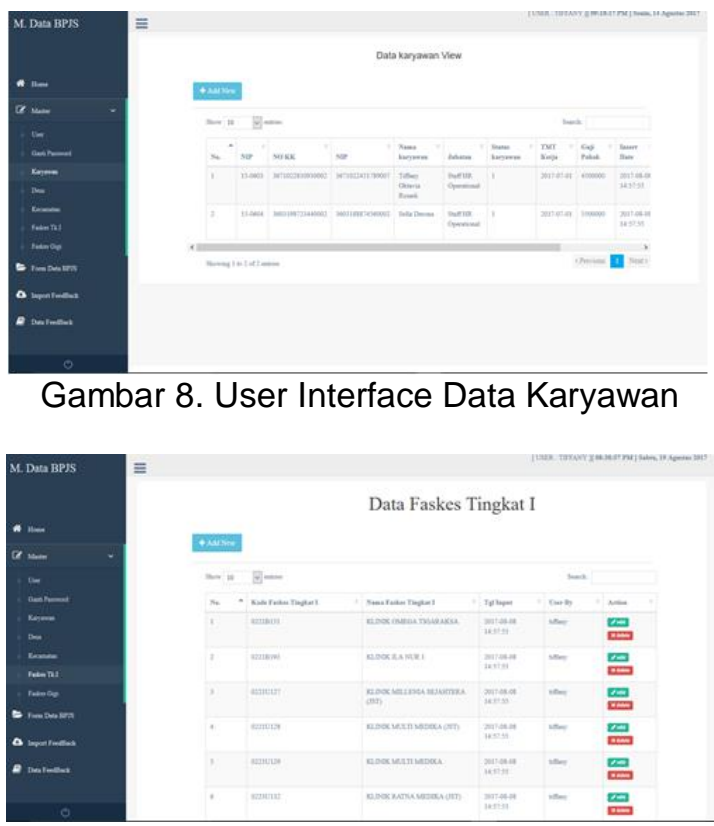

Gambar 9. User Interface Data Faskes
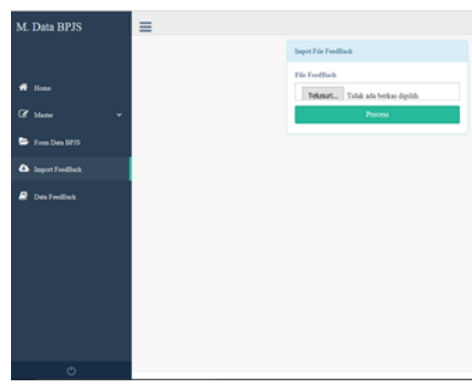

Gambar 10. User Interface Import Feedback

\section{E. KESIMPULAN}

Berdasarkan hasil yang didapat dalam penelitian ini dan disesuaikan dengan tujuannya, maka diperoleh beberapa kesimpulan sebagai berikut : Dengan diterapkannya sistem baru, dapat menyajikan informasi pengelolaan data BPJS Kesehatan dengan tepat dan akurat bila dibandingkan dengan sistem yang sudah ada. Tercapainya kemudahan dalam memberikan informasi karyawan yang gagal validasi pendaftaran. Tercapainya tujuan untuk mempermudah kerja bagian pengurus BPJS Kesehatan dalam mengelola data yang dimiliki. 
Penyimpanan data dalam bentuk database dapat mengurangi tempat penyimpanan, membantu proses pencarian.

\section{DAFTAR PUSTAKA}

[1] Ahmadi, Candra, dan Dadang Hermawan. 2013. E-Business \& ECommerce. Yogyakarta: Penerbit Andi.

[2] Fathansyah. 2012. Basis Data Edisi Revisi. Bandung: Informatika.

[3] Nugroho, Bunafit. 2013. Dasar Pemrograman Web PHP-MySQL dengan Dreamweaver, studi kasus : Sistem Penerimaan Siswa Baru (PSB) Online. Yogyakarta : Gava Media.

[4] Priyadi, Yudi. 2013. Kolaborasi SQL \& ERD dalam Implementasi Database. Yogyakarta: Penerbit Andi.

[5] Priyadi, Yudi. 2014. Kolaborasi SQL \& ERD dalam Implementasi Database. Yogyakarta: Penerbit Andi.

[6] Raharjo, Budi. 2011. Belajar Pemrograman Web Panduan Mudah untuk Pelajar, Mahasiswa, dan Praktisi. Bandung: Penerbit Modula.

[7] Rahman, Su. 2016. Cara Instan Membuat Website. Jakarta: PT Elex Media Komputindo.

[8] S, Rosa A, dan M Salahuddin. 2014. Rekayasa Perangkat Lunak Terstruktur \& Berorientasi Objek, Cetakan Kedua. Bandung: Informatika.

[9] Sutabri, Tata. 2012. Konsep Sistem Informasi. Yoyakarta: Penerbit Andi.

[10] Tantra, Rudy. 2012. Manajemen Proyek Sistem Informasi. Yogyakarta: Penerbit Andi.

[11] Wahana Komputer. 2011. Mastering CMS Programming with PHP \& MySQL. Yogyakarta: Penerbit Andi.

[12] Yatiningsih, Fuji. 2013. Step by Step Belajar Komputer \& Internet untuk Pemula. Yogyakarta: Buku Pintar. 